\title{
Uncertainty Due to Infectious Diseases and Energy Market Volatility
}

\author{
Afees Salisu', Idris Adediran \\ ${ }^{1}$ Centre for Econometric \& Allied Research,, University of Ibadan, Nigeria \\ Keywords: predictability, volatility, pandemics, energy markets \\ https://doi.org/10.46557/001c.14185
}

\section{Energy RESEARCH LETTERS}

Vol. 1, Issue 2, 2020

Motivated by the COVID-19 pandemic, we examine the role of uncertainty due to infectious diseases in predicting energy market volatility using the new dataset on Equity Market Volatility-Infectious Diseases (EMV-ID). We find that the new measure of market uncertainty is a good predictor of energy market volatility in both in-sample and out-of-sample tests. These results have implications for portfolio diversification strategies, which we set aside for future research.

\section{Introduction}

In this short communication, we experiment with the Infectious Disease Equity Market Volatility (EMV-ID) dataset (see Baker et al., 2020) ${ }^{1}$ to tease out information on how uncertainties due to pandemics and epidemics (UPE) affect energy market volatility. This effort is a novel contribution to the energy economics literature. Neither the study of energy market volatility nor its linkage with uncertainty are new. To-date, the literature has been dominated by debate on what constitutes a better predictor of energy market volatility in a horserace between the economic policy uncertainty (EPU) and the equity market uncertainty (EMU); see Wei et al. (2017), Hailemariam et al. (2019), Liang et al. (2019), and Mei et al. (2019) for studies on EPU and Aloui et al. (2016), Baker et al. (2016) and Wen et al. (2019) for studies on EMU. The COVID-19 pandemic has introduced a different dimension to the functioning of energy markets (see Devpura \& Narayan, 2020; Huang \& Zheng, 2020; Narayan, 2020). The present paper contributes to this evolving strand of literature on COVID-19 and energy markets through a study of the role of UPE in shaping energy price volatility. The channel of effect can be explained as follows. In our experiment with the EMV-ID data, we expect uncertainty due to infectious diseases to increase uncertainty in the energy market. Since the pandemic will slowdown transport, trade and economic activity across the globe, investors may engage in panic selling of stocks to minimize risks which may heighten uncertainty in the market (see Diaz \& de Gracia, 2017). This can otherwise be theoretically explained by the theory of irreversible investment that sees investors in energy market delay investment (see Bernanke, 1983; Henry, 1974) and buyers delay spending (see Hamilton, 2003) in the face of energy market uncertainty. The way pandemics can influence energy price volatility is also discussed in Devpura and Narayan (2020) and we refer readers to that paper. We hypothesize that UPE will predict energy market volatility.

Using a popular predictability model, we show strong evidence of energy market volatility predictability due to UPE. This predictability is discovered also over the period of the
COVID-19 pandemic. Our paper contributes to the recent literature by linking pandemics to economic uncertainties resulting from the COVID-19 pandemic (see Bakas \& Triantafyllou, 2020; Ma et al., 2020).

Our work suggests possible portfolio diversification opportunities for investors given that oil market volatility is predictable. While investigating this is outside the scope of this note, we leave this aspect of research for future studies. The rest of the paper is structured as follows. Section 2 has a discussion on data and methodology. Results and discussions appear in Section 3. The final section concludes.

\section{Data and Methodology}

Our data cover two variables, namely the energy market volatility and a measure of uncertainty (EMV-ID), which we refer to as UPE. Both data are obtained from the FRED database of the Federal Reserve Bank of St. Louis. The energy market volatility index used in this study was constructed by the CBOE (the Chicago Board Options Exchange) while the EMV-ID was developed by Baker et al. (2020). The former has been empirically tested over time and studies have established a negative correlation between the volatility index and market returns (see Bouri et al., 2018; Shaikh \& Padhi, 2015). The EMV-ID, however, is still relatively recent and therefore has not received much empirical applications compared to other volatility indexes. We utilize daily data over the period of $3 / 21 / 2011$ and $6 / 4 / 2020$ (including the COVID-19 period) based on data availability and the need to have the same start and end dates for the two series. The analyses are conducted using both the full sample and the sample covering the COVID-19 pandemic. The COVID-19 period analysis is restricted to $2 / 10 / 2020$ (when deaths associated with the pandemic became imminent) to $6 / 4 / 2020$ (when the first draft of the paper was submitted).

For the empirical analysis, we construct a bivariate predictive model, where the energy market volatility is the predicted series while the predictor is UPE (see Westerlund \& Narayan, 2012, 2015):

\footnotetext{
1 A major attraction of the new dataset lies in its scope as it covers uncertainty due to all the known pandemics for over three decades, thus, making it the most comprehensive data on the subject.
} 
Table 1: Preliminary results

\begin{tabular}{|c|c|c|c|c|}
\hline \multirow[t]{2}{*}{ Statistics } & \multicolumn{2}{|l|}{ Full sample } & \multicolumn{2}{|c|}{ COVID-19 sample } \\
\hline & Energy & UPE & Energy & UPE \\
\hline Mean & 24.142 & 1.421 & 62.091 & 28.349 \\
\hline Std. Dev. & 11.180 & 6.074 & 27.330 & 16.114 \\
\hline $\mathrm{ADF}[\mathrm{I}(0)]$ & $-4.619^{* *}$ & $-3.687^{* *}$ & & \\
\hline GARCH $[I(0)]$ & $-8.550^{* * *}$ & $-103.61^{* * *}$ & & \\
\hline $\mathrm{ARCH}(2)$ & $172.24^{* * *}$ & $390.85^{* * *}$ & & \\
\hline $\mathrm{ARCH}(4)$ & $96.65^{* * *}$ & $198.00^{* * *}$ & & \\
\hline $\mathrm{ARCH}(6)$ & $160.52^{* * *}$ & $152.73^{* * *}$ & & \\
\hline Q-stat (2) & $79.847^{* * *}$ & $214.90^{* * *}$ & & \\
\hline Q-stat (4) & $86.682^{* * *}$ & $237.19^{* * *}$ & & \\
\hline Q-stat (6) & $96.237^{* * *}$ & $244.93^{* * *}$ & & \\
\hline $\mathrm{Q}^{2}$-stat (2) & $365.99^{* * *}$ & $799.56^{* * *}$ & & \\
\hline $\mathrm{Q}^{2}$-stat (4) & $559.34^{* * *}$ & $1124.7^{* * *}$ & & \\
\hline$Q^{2}$-stat (6) & $1224.9^{* * *}$ & $1438.8^{* * *}$ & & \\
\hline Persistence & - & $0.9392^{* * *}(0.00719)$ & & \\
\hline Endogeneity & & $0.7238^{* * *}(0.0690)$ & & \\
\hline Nobs & & 2350 & 85 & 85 \\
\hline
\end{tabular}

Note: We limit the formal tests to the full sample due to the small COVID-19 sample period. UPE denotes Uncertainty due to Pandemics \& Epidemics. The symbols ******* \& represent the rejection of the underlying null hypotheses for the formal tests at $1 \%, 5 \%$ \& $10 \%$ levels of significance, respectively. I( $(0)$ indicates that the ADF \& GARCH-based unit root tests are conducted at levels. The GARCH-based unit root test is the one proposed by Narayan and Liu (2015) and it is considered an alternative to the Narayan and Popp (2010) test due to the data frequency used in this study (see also Salisu \& Adeleke, 2016).

$$
v_{t}=\alpha+\sum_{i=1}^{5} \lambda_{i}^{a d j} U P E_{t-i}+\gamma\left(U P E_{t}-\rho_{0} U P E_{t-1}\right)+\eta_{t}
$$

where $v_{t}$ is the energy volatility based on the CBOE calculations; $U P E_{t}$ is the market uncertainty index due to infectious diseases; $\eta_{t}$ is zero mean idiosyncratic error term; and the coefficient $\lambda_{i}^{\text {adj }}$ measures the relative impact of UPE on energy volatility and we allow a maximum of five lags given the 5-day daily data frequency as well as the need to capture more dynamics in the estimation process. Thus, the underlying null hypothesis of no predictability involves a joint (Wald) test that $\sum_{i=1}^{5} \lambda_{i}^{a d j}=0$. Note that the original specification of (1) is given as $v_{t}=\alpha+\lambda U P E_{t-1}+\varepsilon_{t}$; however, to resolve any concern with the endogeneity bias resulting from the correlation between $U P E_{t}$ and $\varepsilon_{t}$ as well as any potential persistence effect, we follow the approach of Lewellen (2004) and Westerlund and Narayan $(2012,2015)$. Thus, the parameter $\lambda_{i}^{a d j}$ is derived as $\lambda^{a d j}=\lambda-\gamma\left(1-\rho_{0}\right)$ (where $\rho_{0}$ measures the degree of persistence in $U P E_{t}$ and is described as the bias adjusted ordinary least squares (OLS) estimator of Lewellen (2004), which corrects for any persistence effect in the predictive model. The additional term $\gamma\left(U P E_{t}-\rho_{0} U P E_{t-1}\right)$ corrects for any endogeneity bias resulting from the correlation between $U P E_{t}$ and $\varepsilon_{t}$ as well as any inherent unit root problem in the $U P E_{t}$ variable. In addi- tion, to resolve the issue of conditional heteroscedasticity effect, Westerlund and Narayan $(2012,2015)$ suggest preweighting all the data by $1 / \hat{\sigma}_{\eta}$ and estimating the resulting equation with the OLS. ${ }^{2}$

\section{Results and Discussion}

We begin the analysis based on the full sample data followed by the results from the COVID-19 sample period. The idea is to see if the UPE can predict energy market volatility regardless of the data sample. Due to space constraints, we briefly present the preliminary results of the data. Table 1 shows an increase in both energy market volatility and UPE during the COVID-19 sample period. This implies a positive relation between UPE and energy market volatility. We also find presence of persistence, endogeneity bias, and conditional heteroscedasticity. The message is for us to control these features of the data in our predictive regression model.

In the main analysis, we focus on the predictability results and forecast evaluation, both of which constitute the main contributions of this study. Panel A of Table 2 contains results and shows that UPE has a positive and significant impact on energy market volatility. This finding is timely in the midst of COVID-19. This finding is consistent with the literature demonstrating that market volatili-

2 See Westerlund and Narayan $(2015,2015)$ for computational details. Another major attraction of this technique lies in its ability to isolate the predictor(s) of interest in the estimation and predictability analyses, thus circumventing parameter proliferation. In other words, the technique helps to limit the predictability analyses to the predictor(s) of interest while it also simultaneously resolves any inherent bias (see Westerlund \& Narayan, 2012; Westerlund \& Narayan, 2015, for the theoretical expositions; and also Narayan \& Gupta, 2015; Narayan et al., 2018; Salisu, Raheem, et al., 2019; Salisu, Swaray, et al., 2019, among others, for recent applications). 
Table 2: Predictability and forecast evaluation results

\begin{tabular}{lcc}
\hline Panel A: Predictability results & & \\
\hline & Full Sample & COVID-19 Sample \\
\cline { 2 - 3 } UPE & $0.037485^{* * *}$ & $0.03590^{* * *}$ \\
& $(0.00012)$ & $(0.0004)$ \\
& {$[306.6762]$} & {$[91.6324]$} \\
Nobs & 2350 & 85 \\
\hline
\end{tabular}

Panel B: In-Sample forecast evaluation

\begin{tabular}{lcccc}
\hline & \multicolumn{3}{c}{ Full Sample } & \multicolumn{3}{c}{ COVID-19 Sample } & Model 2 \\
\cline { 2 - 5 } RMSE & Model 1 & Model 2 & Model 1 & 0.5476 \\
\cline { 2 - 5 } Clark \& West & 0.0820 & 0.2933 & 0.2223 & $0.4997^{* * *}$ \\
& - & $0.0043^{* * *}$ & - & $(0.0817)$ \\
& & $(0.0015)$ & & {$[6.1138]$} \\
Nobs & 1205 & {$[2.8430]$} & 65 & 65 \\
\hline
\end{tabular}

Panel C: Out-of-Sample forecast evaluation [Full-Sample]

\begin{tabular}{lcccccc}
\hline & \multicolumn{3}{c}{ Model 1 } & \multicolumn{3}{c}{ Model 2 } \\
\cline { 2 - 7 } & $\mathrm{h}=10$ & $\mathrm{~h}=20$ & $\mathrm{~h}=30$ & $\mathrm{~h}=10$ & $\mathrm{~h}=20$ & $\mathrm{~h}=30$ \\
\cline { 2 - 7 } RMSE & 0.0820 & 0.0824 & 0.0837 & 0.2928 & 0.2928 & 0.2939 \\
Clark \& West & & & $0.0040^{* * *}$ & $0.0037^{* * *}$ & $0.0030^{* * *}$ \\
& & & & $(0.0015)$ & $(0.0015)$ & $(0.0015)$ \\
Nobs & & & {$[2.6556]$} & {$[2.4267]$} & {$[1.9758]$} \\
\hline
\end{tabular}

Panel D: Out-of-Sample forecast evaluation [COVID-Sample]

\begin{tabular}{lcccccc}
\hline & \multicolumn{3}{c}{ Model 1 } & \multicolumn{3}{c}{ Model 2 } \\
\cline { 2 - 7 } & $\mathrm{h}=5$ & $\mathrm{~h}=10$ & $\mathrm{~h}=20$ & $\mathrm{~h}=5$ & $\mathrm{~h}=10$ & $\mathrm{~h}=20$ \\
\cline { 2 - 7 } RMSE & 0.21615 & 0.2163 & 0.2034 & 0.5285 & 0.5123 & 0.4918 \\
Clark \& West & & & $0.4617^{* * *}$ & $0.4324^{* * *}$ & $0.4001^{* * *}$ \\
& & & & $(0.076984)$ & $(0.072418)$ & $(0.063894)$ \\
& & & & {$[5.997383]$} & {$[5.970464]$} & {$[6.262076]$} \\
Nobs & 70 & 75 & \multirow{2}{*}{85} & 70 & 75 & 85 \\
\hline
\end{tabular}

Note: UPE denotes Uncertainty due to Pandemics \& Epidemics. The reported statistics in Panel A are obtained from the joint significance test of five lags of the index expressed in natural logs. Model 1 incorporates the UPE predictor while Model 2 is the historical average model. Thus, the former is the unrestricted model while the latter is the restricted model. Nobs denotes number of observations. The asterisks ****** \& imply statistical significance at the $1 \%, 5 \%$ \& $10 \%$ levels, respectively. Values in parentheses - () denote standard errors while those reported in square brackets - [ ] are for t-statistics. The results for the Clark \& West test are reported for the model under the null (i.e. Model 2). The RMSE reported for Model 1 is a version of Clark \& West (2007) which adjusts the difference in mean squared prediction errors to account for the additional predictors in the model. The null hypothesis of a zero coefficient is rejected if this statistic is greater than +1.282 (for a one sided 0.10 test),+1.645 (for a one sided 0.05 test) and +2.00 for 0.01 test (for a one sided 0.01 test) (see Clark \& West, 2007).

ty is due to economic policy and financial market uncertainty (see, Aloui et al., 2016; Baker et al., 2016; Hailemariam et al., 2019; Liang et al., 2019; Mei et al., 2019; Wei et al., 2017; Wen et al., 2019).

\subsection{Forecast evaluation}

We further evaluate the forecast performance of Equation (1) by comparing its forecast results with those obtained from a historical average model, which is a typical (baseline) predictive model for most financial and economic series. Since the two models are nested as the historical average is a restricted version of Equation (1), their forecast performance comparison can easily be conducted using the Clark and West (2007) [CW] test. The way the CW test equation is constructed in this, the rejection of the null hypothesis implies superiority of the UPE-based model for energy market volatility over the benchmark model. For the full sample analyses, we adopt a 50:50 data split for the in-sample and out-of-sample forecast evaluations. Three out-ofsample forecast horizons, namely a 10-day, a 20-day and a 30-day ahead forecast horizons are considered. A rolling 
regression approach to forecasting is employed consistent with the forecasting literature (see Salisu, Swaray, et al., 2019; Salisu \& Adeleke, 2016). However, for the COVID-19 sample, we adopt a 75:25 data split due to data limitations.

The results are presented in Table 2 (Panel B for the insample forecast and Panels C \& D for the out-of-sample forecasts). We find that the model that incorporates UPE outperforms the benchmark model that ignores it regardless of the data sample. One clear implication of the results is that investors in the energy market may need to consider this health risk (due to COVID-19) in the valuation of riskadjusted returns for energy stocks in particular and perhaps in their diversification of financial assets in general. Further economic significance tests are needed to confirm these claims which we leave for future studies.

\section{Conclusion}

In this study, we examine the role of uncertainty due to pandemics and epidemics in the predictability of energy market volatility. We utilize the new dataset by Baker et al. (2020) and employ a technique that accommodates the salient features of the relevant series. We find that the new uncertainty data is a good predictor of energy market volatility, with significant in-sample and out-of-sample forecasting ability. This conclusion complements the emerging literature on the vulnerability of the energy market to the COVID-19 pandemic and extending the analysis to other commodity markets will enrich the literature. 


\section{REFERENCES}

Aloui, R., Gupta, R., \& Miller, S. M. (2016).

Uncertainty and Crude Oil Returns. Energy

Economics, 55, 92-100. https://doi.org/10.1016/i.ene c0.2016.01.012

Bakas, D., \& Triantafyllou, A. (2020). Commodity price volatility and the economic uncertainty of pandemics. Economics Letters, 90. https://doi.org/1 0.1016/j.econlet.2020.109283

Baker, S. R., Bloom, N., \& Davis, S. J. (2016). Measuring Economic Policy Uncertainty. The Quarterly Journal of Economics, 131(4), 1593-1636. $\underline{\mathrm{h}}$ ttps://doi.org/10.1093/qje/qjw024

Baker, S. R., Bloom, N., Davis, S. J., \& Terry, S. J. (2020). COVID-Induced Economic Uncertainty. National Bureau of Economic Research. https://doi.or g/10.3386/w26983

Bernanke, B. S. (1983). Irreversibility, uncertainty, and cyclical investment. The Quarterly Journal of Economics, 98(1), 85-106. https://doi.org/10.2307/18 $\underline{85568}$

Bouri, E., Gupta, R., Hosseini, S., \& Lau, C. K. M. (2018). Does global fear predict fear in BRICS stock markets? Evidence from a Bayesian Graphical Structural VAR model. Emerging Markets Review, 34, 124-142. https://doi.org/10.1016/j.ememar.2017.11.0 $\underline{04}$

Clark, T. E., \& West, K. D. (2007). Approximately normal tests for equal predictive accuracy in nested models. Journal of Econometrics, 138(1), 291-311. htt ps://doi.org/10.1016/j.jeconom.2006.05.023

Devpura, N., \& Narayan, P. K. (2020). Hourly oil price volatility: The role of COVID-19. Energy Research Letters, 1(2), In press. https://doi.org/10.46557/001 c. 13683

Diaz, E. M., \& de Gracia, F. P. (2017). Oil price shocks and stock returns of oil and gas corporations. Finance Research Letters, 20, 75-80. https://doi.org/10.1016/ j.frl.2016.09.010

Hailemariam, A., Smyth, R., \& Zhang, X. (2019). Oil prices and economic policy uncertainty: Evidence from a nonparametric panel data model. Energy Economics, 83, 40-51. https://doi.org/10.1016/j.enec o.2019.06.010

Hamilton, J. D. (2003). What is an oil shock? Journal of Econometrics, 113(2), 363-398. https://doi.org/1 0.1016/s0304-4076(02)00207-5
Henry, C. (1974). Investment decisions under uncertainty: The irreversibility effect. American Economic Review, 974(64), 1006-1012.

Huang, W., \& Zheng, Y. (2020). COVID-19: Structural changes in the relationship between investor sentiment and crude oil futures price. Energy Research Letters, 1(2), In press. https://doi.org/10.465 $\underline{57 / 001 c .13685}$

Lewellen, J. (2004). Predicting returns with financial ratios. Journal of Financial Economics, 74(2), 209-235. https://doi.org/10.1016/i.jfineco.2002.11.00 $\underline{2}$

Liang, C., Wei, Y., Li, X., Zhang, X., \& Zhang, Y. (2019). Uncertainty and crude oil market volatility: New evidence. Applied Economics, 52(27), 2945-2959. https://doi.org/10.1080/00036846.2019.1 $\underline{696943}$

Ma, C., Rogers, J. H., \& Zhou, S. (2020). Global Economic and Financial Effects of 21st Century Pandemics and Epidemics. Covid Economics: Vetted and Real-Time Papers, 5, 56-78. https://doi.org/10.21 39/ssrn.3565646

Mei, D., Zeng, Q., Cao, X., \& Diao, X. (2019). Uncertainty and oil volatility: New evidence. Physica A: Statistical Mechanics and Its Applications, 525, 155-163. https://doi.org/10.1016/i.physa.2019.03.043

Narayan, P. K. (2020). Oil price news and COVID-19-Is there any connection? Energy Research Letters, 1(1). https://doi.org/10.46557/001c.13176

Narayan, P. K., \& Gupta, R. (2015). Has oil price predicted stock returns for over a century? Energy Econ, 48, 18-23.

Narayan, P. K., \& Liu, R. (2015). A unit root model for trending time-series energy variables. Energy Economics, 50, 391-402. https://doi.org/10.1016/j.en eco.2014.11.021

Narayan, P. K., Phan, D. H. B., \& Sharma, S. S. (2018). Does Islamic stock sensitivity to oil prices have economic significance? Pacific-Basin Finance Journal, 53, 497-512. https://doi.org/10.1016/i.pacfin.2018.0 $\underline{4.003}$

Narayan, P. K., \& Popp, S. (2010). A new unit root test with two structural breaks in level and slope at unknown time. Journal of Applied Statistics, 37(9), 1425-1438. https://doi.org/10.1080/02664760903039 $\underline{883}$ 
Salisu, A. A., \& Adeleke, A. I. (2016). Further application of Narayan and Liu (2015) unit root model for trending time series. Economic Modelling, 55, 305-314. https://doi.org/10.1016/j.econmod.2016.0 2.026

Salisu, A. A., Raheem, I. D., \& Ndako, U. B. (2019). A sectoral analysis of asymmetric nexus between oil price and stock returns. International Review of Economics \& Finance, 61, 241-259. https://doi.org/1 $\underline{0.1016 / \text { j.iref.2019.02.005 }}$

Salisu, A. A., Swaray, R., \& Oloko, T. F. (2019). Improving the predictability of the oil-US stock nexus: The role of macroeconomic variables. Economic Modelling, 76, 153-171. https://doi.org/1 0.1016/i.econmod.2018.07.029

Shaikh, I., \& Padhi, P. (2015). The implied volatility index: Is 'investor fear gauge' or 'forward-looking'? Borsa Istanbul Review, 15(1), 44-52. https://doi.org/1 0.1016/j.bir.2014.10.001
Wei, Y., Liu, J., Lai, X., \& Hu, Y. (2017). Which determinant is the most informative in forecasting crude oil market volatility: Fundamental, speculation, or uncertainty? Energy Economics, 68, 141-150. http s://doi.org/10.1016/i.eneco.2017.09.016

Wen, F., Zhao, Y., Zhang, M., \& Hu, C. (2019). Forecasting realized volatility of crude oil futures with equity market uncertainty. Applied Economics, 51(59), 6411-6427. https://doi.org/10.1080/0003684 $\underline{6.2019 .1619023}$

Westerlund, J., \& Narayan, P. K. (2012). Does the choice of estimator matter when forecasting returns? Journal of Banking \& Finance, 36(9), 2632-2640. http s://doi.org/10.1016/j.jbankfin.2012.06.005

Westerlund, J., \& Narayan, P. K. (2015). Testing for Predictability in Conditionally Heteroskedastic Stock Returns. Journal of Financial Econometrics, 13(2), 342-375. https://doi.org/10.1093/jifinec/nbu001 